\title{
Emerging paradigms in anti-infective drug design
}

\author{
MICHAEL P. BARRETT ${ }^{1} *$ and SIMON L. CROFT ${ }^{2}$ \\ ${ }^{1}$ Wellcome Trust Centre of Molecular Parasitology, Institute of Infection, Immunity and Inflammation and \\ Glasgow Polyomics, College of Medical, Veterinary and Life Sciences, University of Glasgow, G12 8TA, UK \\ ${ }^{2}$ Faculty of Infectious and Tropical Diseases, London School of Hygiene and Tropical Medicine, London WC1E \\ $7 H T, U K$
}

(Received 17 fune 2013; accepted 19 fune 2013)

\begin{abstract}
The need for new drugs to treat microbial infections is pressing. The great progress made in the middle part of the twentieth Century was followed by a period of relative inactivity as the medical needs relating to infectious disease in the wealthier nations receded. Growing realisation that anti-infectives are needed in many parts of the world, to treat neglected diseases as well as to combat the burgeoning risk of resistance to existing drugs, has galvanised a new wave of research into antimicrobial drugs. The transfer of knowledge from the Pharmaceutical industry relating to the importance of understanding how to target drugs successfully within the body, and improved understanding of how pathogens interact with their hosts, is driving a series of new paradigms in anti-infective drug design. Here we provide an overview of those processes as an introduction to a series of articles from experts in this area that emerged from a meeting entitled "Emerging Paradigms in Anti-Infective Drug Design" held in London on the 17th and 18th September 2012. The symposium was organised jointly by British Society for Parasitology (BSP) and the Biological \& Medicinal Chemistry sector of the Royal Society of Chemistry (RSC) and held at the London School of Hygiene \& Tropical Medicine. The symposium set out to cover all aspects of the identification of new therapeutic modalities for the treatment of neglected and tropical diseases. We aimed to bring together leading scientists from all the disciplines working in this field and cover the pharmacology, medicinal chemistry and drug delivery of potential new medicines. Sessions were held on: "Target diseases and targets for drugs", "Target based medicinal chemistry", "Bioavailability and chemistry", "Targeting intracellular microbes", "Alternative approaches and models", and "New anti-infectives - how do we get there?"

This symposium was organised by Simon Croft (LSHTM) and Mike Barrett (University of Glasgow) for the BSP, and David Alker (David Alker Associates) and Andrew Stachulski (University of Liverpool) for the Biological \& Medicinal Chemistry sector of the RSC.
\end{abstract}

Key words: Anti-infectives, drug design, antimicrobials, pharmacokinetics.

\section{INTRODUCTION}

Microbial pathogens remain responsible for around one quarter of all human deaths (Wang et al. 2012) with an overwhelming majority of these in the less well developed nations. Finding drugs to kill pathogens should be relatively easy given that they are genetically distinct from humans with a plethora of potentially selective drug targets. However, in many instances, the identification of 'druggable' targets alone has not been sufficient to underpin new drug development. Difficulties in reaching targets can relate to many issues including differential expression during complex life-cycles and, crucially, interactions between host and pathogen that

* Corresponding author: Wellcome Trust Centre of Molecular Parasitology, Institute of Infection, Immunity and Inflammation and Glasgow Polyomics, College of Medical, Veterinary and Life Sciences, University of Glasgow, G12 8TA, UK. E-mail: michael.barrett@, glasgow.ac.uk influence exposure. Drugs have been used to cure microbial infections for centuries with natural products being predominant. These include quinine, a product of the Peruvian Cinchona tree, used to treat fevers for well over four hundred years and the antimicrobial metabolites produced by fungi and soil-dwelling bacteria which, from penicillin to ivermection, transformed health in the 20th century (Greenwood, 2008). It was also the search for new antimalarials that spawned 'rational chemotherapy' from the use of methylene blue (Guttman and Ehrlich, 1891). The chemical derivation of mepacrine, chloroquine and other pharmaceuticals offer key early examples of medicinal chemistry establishing structure-activity relationships to optimize drugs (Greenwood, 1995).

Progress in antimicrobial therapy reached its zenith in the period from 1950 to 1980 when a plethora of new families of antibiotics were found to target different proteins, nucleic acids and membrane components (Greenwood, 2008). The final years of 
the twentieth century, however, witnessed a dramatic decrease in discovery and development of antiinfective drugs, partly due to the fact that the 'low hanging fruit' had already been picked, partly due to a perception that adequate coverage was now provided for antimicrobial chemotherapy and partly due to the relatively low returns on investment on anti-infectives compared with drugs aimed at chronic diseases in affluent nations (Piddock, 2012). The reductionist claims of molecular biology led to quests for compounds to inhibit proteins that, with the benefit of hindsight, had little prospect of moving towards drugs. In the past few years, a number of key innovations have started to reverse this process. At the economic level, a realization that profits from antimicrobials, particularly those aimed at diseases of the developing world, were insufficient to meet the costs in development, stimulated the establishment of a series of product development partnerships (PDPs) aiming to bring compounds forward (Croft, 2005; Nathan, 2012). The appearance of these organizations, over a period when large pharmaceutical companies was finding it increasingly difficult to license small molecules for any disease, has also led to industrial re-engagement with pathogen-based disease (Gamo et al. 2010; Witty, 2011). The emergence of a previously unthinkable willingness to release intellectual property on compounds that cure diseases like malaria, tuberculosis and the neglected tropical diseases has been a revelation. At the same time, the experiences from the pharmaceutical industry on the centrality of pharmacology to the drug development process led to a new realism in the choice of chemotypes that are suitable for further development as antimicrobial agents. As a consequence, the last five years have seen the appearance of pipelines of compounds entering clinical trials to treat several of the diseases associated with poverty (www.mmv.org; www.tballinance.org; www.dndi.org). It is critical that this momentum is sustained if we are to defeat some of mankind's most persistent scourges and to expand this vision to include novel antibacterials in an era where drug resistance is threatening human and animal health.

In spite of our knowledge of the aetiological agents of most infectious diseases, humankind has been woefully inept at their control, let alone eradication. To date, the only human infectious microbial agent to have been eradicated is the small pox virus targeted by an intensive vaccination campaign. Currently optimism exists that two more microbes might be in line for eradication. The polio virus, also targeted by a vaccination campaign (Minor, 2012) and Guinea worm (Centers for Disease Control and Prevention, 2012), whose demise is being brought about through a public health-based campaign of filtering drinking water that carries the Cyclops arthropods that transmit the worm larvae have declined substantially in incidence. In the meantime novel human-infectious agents are emerging. For example, recent influenza (Watanabe et al. 2012) and Corona virus (Weinstein, 2004) outbreaks have caused alarm worldwide. Also of concern has been the rapid emergence and spread of resistance to existing antimicrobial drugs from hospitals. The ability of resistance genes to spread in microbial communities has demonstrated how dangerous the indiscriminate use of antibiotics in domestic livestock can be (Garcia-Alvarez, 2012). Tuberculosis bacteria resistant to most of the current drugs now exist (Haydel, 2010). In malaria, most of the drugs used 20 years ago are useless due to wide spread resistance. Even use of the artemisinin derivatives is threatened by emerging resistance (White, 2012). The requirement for a robust and sustained pipeline of anti-microbial drugs is imperative if we are to control microbial infections in the developed world and turn the tide on the multitude of infectious agents that continue to thwart society in the developing world.

ANTI-PATHOGEN AND ANTI-TARGET-BASED SCREENS, SUCCESSES AND DISAPPOINTMENTS

During the 1980s it became relatively easy to identify genes that encode proteins and to produce those proteins in quantities sufficient to enable screening of series of chemical compounds for inhibitory activity. This process accelerated with the advent of whole genome sequencing in the late 1990s and the expansion of those technologies into the 2000s driven by the completion of genome sequences for Mycobacterium tuberculosis (Cole et al. 1998), Plasmodium falciparum (Wirth, 2002) and Leishmania and Trypanosoma species (El-Sayed et al. 2005). It was often quoted that all potential drug targets were now in reach, and miniaturized and robotic systems made the screening of millions of compounds feasible.

The scientific literature of the 1990s into the 2000s is replete with descriptions of proteins whose activity could be inhibited by a range of molecules, few of which had the physicochemical properties compatible with potential for use as drugs. Molecular structures of proteins made it possible to predict which chemical ligands could bind within active sites and a multitude of studies were performed to find such molecules and use them as leads to generate more compounds. In the trypanosomatids, enzymes involved in the metabolism of the unusual thiol compound, named trypanothione (Fairlamb et al. 1985), were seen as particularly useful drug targets given their exclusive presence in these protozoa and absence in man. However, in spite of a multitude of screening and structure-based efforts to identify selective inhibitors this system, like many others, failed to yield credible compounds for development as drugs (Gilbert, 2013). The development of genetic methods that enabled testing of enzyme essentiality 
appeared to offer a short cut to ensure the value of particular targets. A seminal paper from investigators at GSK in 2007, however, reported that the systematic expression of scores of target proteins and their screening against libraries of hundreds of thousands of compounds yielded absolutely nothing in terms of new antimicrobials (Payne et al. 2007). Other companies had been suffering similarly frustrating times and the academic laboratories involved in rather lower-level throughput screening could report the same. Target-based screening has to date failed to deliver its full potential with a few notable exceptions including new inhibitors of dihydrofolate reductases, DNA topoisomerases and C14- $\alpha$-sterol demethylases in fungi. Notwithstanding, today within the MMV portfolio there are compounds whose activity was aimed at specific targets including dihydroorotate dehydrogenase (Booker et al. 2010). The electron transport chain, essential in Plasmodium pyrimidine biosynthesis, has also been targeted with potent quinolone-based compounds (Stocks et al. 2013). Developing more sophisticated modelling methods continues to contribute towards lead compound identification and refinement against specific targets but also increasing the use of physicochemical constraints to enhance the probability of compounds emerging with drug-like features (Cunningham et al. 2013). In the trypanosomatids, protein farnesyl transferase and $N$-myristoyl transferase were shown to be targets against which very potent compounds could be designed (Frearson et al. 2010). However, in these latter cases too there has been a difficulty in adapting compounds that are excellent inhibitors of the enzymes and potent killers of the pathogens to drugs (Tate et al. 2013). These difficulties relate to the problems surrounding pharmacokinetics and pathogen tropisms within hosts, but optimism remains that as our knowledge of drug interactions within the mammalian system increases, so potent inhibitors can be adapted to allow them to reach their targets.

Many of the compounds developed as antimicrobials emerged well before the advent of molecular targets for drugs and even before the luxury of effective in vitro cultivation methods. The compounds were found by screening of chemicals against pathogens within animal models, for example around 300000 compounds were screened as potential antimalarials in the 1970s (Ockenhouse et al. 2005). Those screening programmes, by necessity in the absence of the reductionist approaches that came later, took the entire system into account. That is to say the chemicals they used needed to inhibit targets within pathogens, themselves distributed to infected tissues within the host. Hence any compounds which did not possess pharmacological properties compatible with suitable stability and distribution within the host would never be selected. Today we are reverting towards such a 'systems pharmacology' (Iyengar, 2012) taking into account all of the parameters required to produce a suitable drug. As available compound numbers have increased, large-scale in vivo screening is not viable, hence it is usually necessary to determine PK properties of drugs independently of potency and then to marry datasets prior to choosing those which are selected for in vivo screening.

There is now a general acceptance that the best antimicrobial agents have emerged by screening compound libraries against whole organisms in vitro and then taking hits to optimize for their in vivo pharmacology. Thus the antimalarial pipeline currently contains over a dozen compounds, most of which came through screening against the whole organism rather than by aiming at a particular target. For tuberculosis, the kinetoplastid protozoa and many bacteria, the same is true. A challenge then is to identify targets within the parasites that are functional in the mammalian stages of the life-cycle. The selection of resistant strains can help to identify the target with whole genome sequencing pointing to mutations that lead to resistance (provided the mutations are within the target rather than affecting other aspects of drug-pathogen interaction such as entry into or efflux from cells). The use of highthroughput RNAi screens in trypanosomes has proven hugely successful in identifying loss of function mutations that can allow parasites to grow in the presence of drugs and thus point to potential modes of action (Horn, 2013). Another route has been to measure the metabolome of pathogens treated with compounds in attempts to identify whether enzyme products and substrates change in ways pointing to selective inhibition (Creek and Barrett, 2013). The phenotypic whole-organism screens also pick out compounds that may act against multiple targets, and 'polypharmacology' where multiple targets are hit by a single drug certainly contributes to the superiority of the phenotypic screening route; clearly exampled in kinases (Knight et al. 2010). However, many compounds that are highly potent in phenotypic screens still fail as drugs as the other part of the 'system' (i.e. interactions within the host's biochemical environment) must also be surmounted. It is the appreciation of these pharmacological criteria that is now guiding the development of improved antimicrobial agents. Expression of target genes in highly tractable organisms like yeast offers another route to seek inhibitors of enzymes that function within a cellular context, and has been successfully used to identify new inhibitors of inositol phosphorylceramide synthase from Leishmania (Norcliffe et al. 2013).

THE GROWTH OF PK, PD AND ADME-TOX-BASED APPROACHES

It is critical to optimize pharmacological features to ensure that drugs are not toxic to host animals at 
doses required to kill pathogens. Moreover, compounds must be distributed to the tissues in which their target pathogens have localized and they must be stable enough and remain available in sufficient quantities to exert their anti-pathogen effect. Several examples exist whereby compound selection was driven primarily through optimization of $\mathrm{PK} / \mathrm{PD}$ parameters. For example, the benzoxaborole class of compounds were shown to have some activity against Trypanosoma brucei in vitro (albeit of relatively low potency) - but in vivo they were shown to be efficacious against the $T$. brucei acute mouse model (Jacobs et al. 2011). Since the standard model for Stage 2 HAT involves a six month follow-up post-treatment to seek parasites in blood, SCYNEXIS pursued a lead optimization programme to determine levels of compound in brain and compared these to drug doses needed to kill and the time of exposure required. SCYX-7158, which emerged from this work is now in phase 1 clinical trials (Wring et al. 2013).

For Plasmodium, MMV has implemented a very rigorous series of protocols to enable $\mathrm{PK}$ and $\mathrm{PD}$ profiling of compounds, with plasma half-life, protein binding and volume of distribution, as well as the PD property of rate of kill (Anthony et al. 2012) seen as key criteria to advance compounds. Only compounds that combine satisfactory PK/PD relationships are now considered within the MMV target product profile (TPP) of single-dose drugs for radical cure (Jimanez-Diaz et al. 2013). For leishmaniasis and tuberculosis it has proven remarkably difficult to identify compounds that are efficacious against pathogens within the acidic environment of the phagolysosomes in which they thrive in host macrophages. The presence of these pathogens within granulomas that further restrict the local accumulation of drugs (Kjellsson et al. 2012) has yet to be surmounted in investigative PK studies. No available animal models give a reliable reflection of the human host environment which contributes to the difficulties that have been so problematic in identifying suitable drugs for these organisms. As we better appreciate these issues, so the need for better, more predictive in vitro and in vivo models for drug development becomes ever more clear.

\section{THE CHANGING DRUG DEVELOPMENT \\ LANDSCAPE, PRODUCT DEVELOPMENT \\ PARTNERSHIPS, RE-ENGAGING PHARMA AND \\ OPEN SOURCE DRUG DEVELOPMENT}

By the late 1990s, a series of mergers within the pharmaceutical industry, accompanied by business models dependent upon identifying block-buster drugs that could be sold at high prices for the chronic diseases common in the affluent west, were impacting adversely on anti-pathogen drug development. Short doses of cheap curative drugs were the norm for most infectious diseases within the developed world. For the cohort of diseases that afflict predominantly the world's poorest people, the required investments reaching many millions of dollars for development, could not be put forward with no prospect of a return. It was to this back-drop that in 1998 the Global Alliance for Tuberculosis was founded followed by MMV in 1999. In 2003, the Drugs for Neglected Diseases initiative emerged with a remit to seek new agents for HAT, leishmaniasis and Chagas disease (Don and Ioset, 2013). Other PDPs, such as the Consortium for Parasitic Drug Development (CPDD), received substantial backing from the Bill and Melinda Gates Foundation to take the orally available diamidine pro-drug, pafuramidine, forward for HAT (Paine et al. 2010) and the Institute of One World Health (iOWH) took paromomycin forward for visceral leishmaniasis (Sundar et al. 2007). Elsewhere academic-based laboratories, for example the Drug Discovery Unit in Dundee and the Center for Discovery and Innovation in Parasitic Diseases at $\mathrm{UCSF}$, have dedicated themselves to drug discovery with the PDPs offering natural points for handing over optimized leads for clinical development. The growth of the PDPs and increased level of sophistication in academic drug discovery has also seen a new acceptance within the pharmaceutical industry that competence is now available for them to engage in the area. Pharmaceutical companies have made compound libraries available for large screens against HAT, leishmania, Chagas disease, malaria, tuberculosis and other infections, and significant hits have emerged. Moreover, several large pharmaceutical companies have also re-launched their own programmes in drug discovery for tropical diseases. GSK Tres Cantos (Spain) is one of the leaders, making available the data from their malaria screening programme. In addition the GSK Open lab offers opportunities for academics and small biotech companies to work within a GSK development environment (Jimanez-Diaz et al. 2013). Novartis established a tropical disease research facility in Singapore in 2004, with a current focus on malaria (Smith et al. 2013), dengue and HAT. The adoption by industry of pre-competitive models for drug discovery emulates many of these changes and offers opportunities to extend public private interactions into new disease areas. Another interesting growth area has been the emergence of open-source drug discovery where ideas on chemical synthesis can be exchanged on line to accelerate the resolution of problems in chemical synthesis as was successfully demonstrated in separating enantiomers of the antischistosomal drug praziquantel (Robertson et al. 2013).

A largely overlooked area of anti-pathogen chemotherapy has been the development of novel drugs against helminth infections. Given that billions of people the world over are afflicted with one or more 
parasitic helminth species it has been extraordinary that so little effort has gone into developing novel agents against the human helminthiases (Keiser and Utzinger, 2010). The fact that several orally available, relatively safe and efficacious drugs, developed initially for the veterinary market, exist has been a disincentive towards development, as has the fact that many of the helminthiases are not in themselves life threatening. However, with the realization that these neglected tropical diseases do have a huge impact on human populations, interest in this area has been reinvigorated (Hotez et al. 2008). With it comes a new series of challenges around targeting organisms that pass through multiple life-cycle stages in their host (targeting adult vs larval worm stages requires different compounds in many cases) (Taylor et al. 2013). The presence of relatively large organisms, with multiple organ systems and a protective cuticle is presenting a new wave of challenges for those interested in developing drugs for these diseases.

\section{POTENTIAL RISKS TO A DECADE OF PROGRESS}

For the first time in history a robust pipeline of rationally selected compounds for development against malaria has been developed (Burrows et al. 2013). Elsewhere, less robust pipelines, but pipelines nevertheless, have emerged for treatment of human African trypanosomiasis, leishmaniasis, Chagas disease, tuberculosis and other neglected diseases. The paradigms that have emerged to create these pipelines are now being applied to other parasitic and bacterial diseases. Comparing the status of the different pipelines indicates that the tropism and behaviour of pathogens within the host is a main determinant with the ease by which we may target drugs to them. From an optimist's perspective our increased appreciation of the barriers that selectively hinder development of drugs for different pathogens encourages the belief that the dissection of these problems and adoption of pharmacological approaches to breach the blood-brain barrier, granuloma barriers or the harsh acidic environment of the macrophage mean a way ahead is possible.

The focus must now be to sustain the successes of the past decade to ensure the tools are available for more effective treatment of patients, control of diseases in populations and eventual elimination or eradication. For some diseases, for example malaria, the demands are high with need for different types of drugs, exhibiting a variation of mechanisms of action and pharmacokinetic properties, to be used for different purposes in treatment and control (Burrows et al. 2013). For malaria, this has led to new definitions of target clinical profiles and illustrates the need for several new drugs, and safe effective multi-stage combinations of these drugs. Combination therapy has long been a complexity for those developing drugs for tuberculosis where issues of drug-drug interaction and pharmaceutical formulation have to be addressed in parallel with clinical development. Other demands face neglected diseases. In the case of HAT, the incidence of the disease has declined substantially over the past decade, with fewer than 7000 new cases reported in 2011 (Simarro et al. 2012). This has led many funding agencies to question whether there is a need to continue investing in new tools when existing tools, such as the nifurtimox-eflornithine combination (NEC'T), can be demonstrably effective when used correctly, despite the facts that these existing tools are generally highly unsatisfactory as drugs. Resistance to eflornithine is very readily selected (Vincent et al. 2010) and reports of treatment failure to eflornithine monotherapy are already emerging from parts of Africa. The pipeline is not yet sufficiently robust to cover loss of drugs to resistance. For leishmaniasis too, the existing drugs suffer many limitations and the realization that for every clinically recognized case of leishmaniasis there are probably 10 undiagnosed, asymptomatic infections offering a potential reservoir that will seriously hinder any elimination programme. Liposomal amphotericin B and new combinations have been hailed as a tool for elimination and offer the potential advantage of shorter course treatments against visceral leishmaniasis where cost, delivery to populations, and stability plus differences in efficacy between India and Sudan remain key issues (Croft and Olliaro, 2011).

There must be a degree of pragmatism among the communities involved in developing drugs for these pathogens. The paradigm of bringing compounds into PDPs, where robust pharmacological data combines with potency studies to drive development, clearly works. Further expansion of the role of pharmaceutical companies, integration of the activities of existing PDPs, support for innovation in the academic and biotech sectors, enhanced sharing of information and an insistence on global standards for the development of new compounds for these diseases is the way ahead. The implementation of new drugs in programmes for the treatment, control and elimination/eradication of these diseases also requires more forethought, planning and commitment of funds and support for health systems.

\section{ACKNOWLEDGEMENTS}

The meeting organisers are grateful to Cambridge University Press, Cipla, Novartis, Pharmidex and SCYNEXIS for their generous sponsorship of the meeting.

\section{REFERENCES}

Anthony, M.P., Burrows, J. N., Duparc, S., Moehrle, J. J. and Wells, T.N. (2012). The global pipeline of new medicines for the control and elimination of malaria. Malaria fournal 11, 316.

Booker, M. L., Bastos, C. M., Kramer, M. L., Barker, R. H., Jr., Skerlj, R., Sidhu, A. B., Deng, X., Celatka, C., Cortese, J.F., 
Guerrero Bravo, J. E., Crespo Llado, K. N., Serrano, A. E., AnguloBarturen, I., Jiménez-Díaz, M. B., Viera, S., Garuti, H., Wittlin, S. Papastogiannidis, P., Lin, J.W., Janse, C. J., Khan, S. M. Duraisingh, M., Coleman, B., Goldsmith, E. J., Phillips, M. A., Munoz, B., Wirth, D. F., Klinger, J. D., Wiegand, R. and Sybertz, E (2010). Novel inhibitors of Plasmodium falciparum dihydroorotate dehydrogenase with anti-malarial activity in the mouse model. Fournal of Biological Chemistry 285, 33054-33064.

Burrows, J. N., Burlot, E., Campo, B., Cherbuin, S., Jeanneret, S., Leroy, D., Spangenberg, T., Waterson, D., Wells, N. C. and Willis, P (2013). Antimalarial drug discovery - the path towards eradication. Parasitology 141, 128-139.

Centers for Disease Control and Prevention. (2012). Progress toward global eradication of dracunculiasis-January 2011-June 2012. Morbidity and Mortality Weekly Report 61, 854-857.

Cole, S. T., Brosch, R., Parkhill, J., Garnier, T., Churcher, C., Harris, D., Gordon, S. V., Eiglmeier, K., Gas, S., Barry, C. E., III Tekaia, F., Badcock, K., Basham, D., Brown, D., Chillingworth, T. Connor, R., Davies, R., Devlin, K., Feltwell, T., Gentles, S., Hamlin, N., Holroyd, S., Hornsby, T., Jagels, K., Krogh, A., McLean, J., Moule, S., Murphy, L., Oliver, K., Osborne, J., Quail, M. A., Rajandream, M. A., Rogers, J., Rutter, S., Seeger, K., Skelton, J., Squares, R., Squares, S., Sulston, J. E., Taylor, K., Whitehead, S. and Barrell, B. G. (1998). Deciphering the biology of Mycobacterium tuberculosis from the complete genome sequence. Nature 393, 537-544

Creek, D. J. and Barrett, M.P. (2013). Determination of antiprotozoal drug mechanisms by metabolomics approaches. Parasitology 141, 83-92.

Croft, S. L. (2005). Public-private partnership: from there to here Transaction of the Royal Society of Tropical Medicine and Hygiene 99 (Suppl. 1), S9-S14.

Croft, S. L. and Olliaro, P. (2011). Leishmaniasis chemotherapy challenges and opportunities. Clinical Microbiology Infection 17, 1478-1483. Cunningham, F., McPhillie, M. J., Johnson, A. P. and Fishwick, C. W. G. (2013). An in silico structure-based approach to antiinfective drug discovery. Parasitology 141, 17-27.

Don, R. and Ioset, J. R. (2013). Screening strategies to identify new chemical diversity for drug development to treat kinetoplastid infections. Parasitology 141, 140-146.

El-Sayed, N. M., Myler, P. J., Blandin, G., Berriman, M., Crabtree, J. Aggarwal, G., Caler, E., Renauld, H., Worthey, E. A., HertzFowler, C., Ghedin, E., Peacock, C., Bartholomeu, D. C., Haas, B. J., Tran, A. N., Wortman, J.R., Alsmark, U.C., Angiuoli, S. Anupama, A., Badger, J., Bringaud, F., Cadag, E., Carlton, J. M., Cerqueira, G. C., Creasy, T., Delcher, A. L., Djikeng, A., Embley, T. M., Hauser, C., Ivens, A. C., Kummerfeld, S. K., Pereira-Leal, J. B., Nilsson, D., Peterson, J., Salzberg, S. L., Shallom, J., Silva, J. C., Sundaram, J., Westenberger, S., White, O. Melville, S.E., Donelson, J.E., Andersson, B., Stuart, K.D. and Hall, N. (2005). Comparative genomics of trypanosomatid parasitic protozoa. Science 309, 404-409.

Fairlamb, A.H., Blackburn, P., Ulrich, P., Chait, B. T. and Cerami, A. (1985). Trypanothione: a novel bis(glutathionyl)spermidine cofactor for glutathione reductase in trypanosomatids. Science 227 1485-1487.

Frearson, J. A., Brand, S., McElroy, S. P., Cleghorn, L. A., Smid, O., Stojanovski, L., Price, H. P., Guther, M. L., Torrie, L. S., Robinson, D. A., Hallyburton, I., Mpamhanga, C. P., Brannigan, J. A., Wilkinson, A. J., Hodgkinson, M., Hui, R., Qiu, W., Raimi, O. G., van Aalten, D. M., Brenk, R., Gilbert, I. H., Read, K. D., Fairlamb, A. H., Ferguson, M. A., Smith, D. F. and Wyatt, P. G. (2010). $N$-myristoyltransferase inhibitors as new leads to treat sleeping sickness. Nature 464 728-732.

Gamo, F. J., Sanz, L. M., Vidal, J., de Cozar, C., Alvarez, E. Lavandera, J. L., Vanderwall, D. E., Green, D. V., Kumar, V., Hasan, S., Brown, J. R., Peishoff, C. E., Cardon, L. R. and GarciaBustos, J. F. (2010). Thousands of chemical starting points for antimalarial lead identification. Nature 465, 305-310.

Garcia-Alvarez, L., Dawson, S., Cookson, B. and Hawkey, P. (2012). Working across the veterinary and human health sectors. Fournal of Antimicrobial Chemotherapy 67(Suppl. 1):i37-i49.

Gilbert, I. H. (2013). Target-based drug discovery for human African trypanosomiasis: selection of molecular target and chemical matter. Parasitology 141, 28-36.

Greenwood, D. (1995). Conflicts of interest: the genesis of synthetic antimalarial agents in peace and war. Fournal of Antimicrobial Chemotherapy 36, $857-872$.
Greenwood, D. (2008). Antimicrobial drugs. Chronicle of a Twentieth Century Medical Triumph, pp. 368. Oxford University Press, Oxford, UK. Guttman, P. and Ehrlich, P. (1891). Ueber die Wirkung des Methylenblau bei Malaria. Berliner Klinische 28, 953-956.

Haydel, S. E. (2010). Extensively drug-resistant tuberculosis: a sign of the times and an impetus for antimicrobial discovery. Pharmaceuticals (Basel) 3, 2268-2290

Horn, D. (2013). High-throughput decoding of drug targets and drug resistance mechanisms in African trypanosomes. Parasitology 141, $77-82$.

Hotez, P. J., Brindley, P. J., Bethony, J. M., King, C. H., Pearce, E. J. and Jacobson, J. (2008). Helminth infections: the great neglected tropical diseases. Fournal of Clinical Investigation 118, 1311-1321.

Iyengar, R., Zhao, S., Chung, S. W., Mager, D. E. and Gallol, J. M. (2012). Merging Systems Biology with Pharmacodynamics. Science Translational Medicine 4, ps7.

Jacobs, R. T., Nare, B., Wring, S. A., Orr, M. D., Chen, D., Sligar, J. M., Jenks, M.X., Noe, R. A., Bowling, T.S., Mercer, L. T., Rewerts, C., Gaukel, E., Owens, J., Parham, R., Randolph, R., Beaudet, B., Bacchi, C. J., Yarlett, N., Plattner, J. J., Freund, Y., Ding, C., Akama, T., Zhang, Y. K., Brun, R., Kaiser, M., Scandale, I. and Don, R. (2011). SCYX-7158, an orally-active benzoxaborole for the treatment of stage 2 human African trypanosomiasis. PLoS Neglected Tropical Diseases 5, e1151.

Jimanez-Diaz, M. B., Viera, S., Fernandez-Alvaro, E. and AnguloBarturen, I. (2013). Animal models of efficacy to accelerate drug discovery in malaria. Parasitology 141, 93-103.

Keiser, J. and Utzinger, J. (2010). The drugs we have and the drugs we need against major helminth infections. Advances in Parasitology $\mathbf{7 3}$ 197-230.

Kjellsson, M.C., Via, L.E., Goh, A., Weiner, D., Low, K. M., Kern, S., Pillai, G., Barry, C. E., III and Dartois, V. (2012) Pharmacokinetic evaluation of the penetration of antituberculosis agents in rabbit pulmonary lesions. Antimicrobial Agents and Chemotherapy 56, $446-457$

Knight, Z. A., Lin, H. and Shokat, K. M. (2010). Targeting the cancer kinome through polypharmacology. Nature Reviews Cancer 10 , 130-137.

Minor, P. D. (2012). Polio vaccines and the eradication of poliomyelitis. Lancet 380, 454-455.

Nathan, C. (2012). Fresh approaches to anti-infective therapies. Science Translational Medicine 4, 140sr2.

Norcliffe, J. L., Alvarez-Ruiz, J. J., Martin-Plaza, P. G. and Denny, P. W. (2013). The utility of yeast as a tool for cell-based, targetdirected high-throughput screening. Parasitology 141, 8-16.

Ockenhouse, C. F., Magill, A., Smith, D. and Milhous, W. (2005). History of U.S. military contributions to the study of malaria. Military Medicine 170(Suppl.), 12-16.

Paine, M. F., Wang, M.Z., Generaux, C. N., Boykin, D.W. Wilson, W. D., De Koning, H. P., Olson, C. A., Pohlig, G., Burri, C., Brun, R., Murilla, G. A., Thuita, J. K., Barrett, M. P. and Tidwell, R. R. (2010). Diamidines for human African trypanosomiasis. Current Opinion in Investigative Drugs 11, 876-883.

Payne, D. J., Gwynn, M. N., Holmes, D. J. and Pompliano, D. L. (2007). Drugs for bad bugs: confronting the challenges of antibacterial discovery. Nature Reviews Drug Discovery 6, 29-40.

Piddock, L. J. (2012). The crisis of no new antibiotics-what is the way forward? Lancet Infectious Diseases 12, 249-253.

Robertson, M., Ylioja, P., Woelfle, M., Robins, M., Williamson, A. Badiola, K., Olliaro, P., Wells, T. N.C. and Todd, M. H. (2013). Open source drug discovery - A limited tutorial. Parasitology 141, 148-157.

Simarro, P.P., Cecchi, G., Franco, J.R., Paone, M., Diarra, A., Ruiz-Postigo, J. A., Fèvre, E. M., Mattioli, R. C. and Jannin, J. G. (2012). Estimating and mapping the population at risk of sleeping sickness. PLoS Neglected Tropical Diseases 6, e1859.

Smith, P. W., Diagana, T. T. and Yeung, B. K. S. (2013). Progressing the global antimalarial portfolio: finding drugs which target multiple Plasmodium life stages. Parasitology 141, 66-76.

Stocks, P. A., Barton, V., Antoine, T., Biagnini, G. A., Ward, S. A. and O'Neill, P. M. (2013). Novel inhibitors of the Plasmodium falciparum electron transport chain. Parasitology 141, 50-65.

Sundar, S., Jha, T.K., Thakur, C.P., Sinha, P.K. and Bhattacharya, S. K. (2007). Injectable paromomycin for Visceral leishmaniasis in India. New England Fournal of Medicine 356, 2571-2581.

Tate, E. W., Bell, A.S., Rackham, M. D. and Megan, H. (2013). $N$-Myristoyltransferase as a potential drug target in malaria and leishmaniasis. Parasitology 141, 37-49. 
Taylor, M. J., Hoerauf, A., Townson, S., Slatko, B. and Ward, S. (2013). Anti-Wolbachia (A·WOL) drug discovery and development: safe macrofilaricides for onchocerciasis and lymphatic filariasis. Parasitology 141, 119-127.

Vincent, I. M., Creek, D., Watson, D. G., Kamleh, M. A., Woods, D. J., Wong, P.E., Burchmore, R. J. and Barrett, M.P. (2010). A molecular mechanism for eflornithine resistance in African trypanosomes. PLoS Pathogens 6, e1001204.

Wang, H., Dwyer-Lindgren, L., Lofgren, K. T., Rajaratnam, J. K., Marcus, J. R., Levin-Rector, A., Levitz, C. E., Lopez, A. D. and Murray, C. J. (2012). Age-specific and sex-specific mortality in 187 countries, 1970-2010: a systematic analysis for the Global Burden of Disease Study 2010. Lancet 380, 2071-2094.

Watanabe, Y., Ibrahim, M.S., Suzuki, Y. and Ikuta, K. (2012). The changing nature of avian influenza A virus (H5N1). Trends in Microbiology 20, 11-20.
Weinstein, R. A. (2004). Planning for epidemics-the lessons of SARS. New England Fournal of Medicine 350, 2332-2334.

White, N. J. (2012). Counter perspective: artemisinin resistance: facts, fears, and fables. American Fournal of Tropical Medicine and Hygiene 87, 785 .

Wirth, D. F. (2002). Biological revelations. Nature 419, 495-496.

Witty, A. (2011). New strategies for innovation in global health: a pharmaceutical industry perspective. Health Affairs (Millwood) 30, 118-126.

Wring, S., Gaukel, E., Nare, B., Jacobs, R., Beaudet, B., Bowling, T., Mercer, L., Bacchi, C., Yarlett, N., Randolph, R., Parham, R., Rewarts, C., Platerner, J. and Don, R. (2013). Pharmacokinetics and pharmacodynamics utilizing unbound target tissue exposure as part of a disposition-based rationale for lead optimization of benzoxaboroles in the treatment of stage 2 Human African Trypanosomiasis. Parasitology 141, 104-118. 